\title{
CUSTO PARA O ATENDIMENTO DO DESEMPENHO ACÚSTICO EM SISTEMAS DE VEDAÇÕES HORIZONTAIS E VERTICAIS CONFORME NBR 15575
}

\author{
COST FOR ACOUSTIC PERFORMANCE ASSISTANCE IN HORIZONTAL AND \\ VERTICAL SEALING SYSTEMS IN ACCORDANCE WITH NBR 15575
}

\section{RESUMO}

Com a entrada em vigor da NBR 15575 (ABNT, 2013), o desempenho das edificações passou a ter maior destaque no âmbito da construção civil. Entre as exigências trazidas pela norma de desempenho, está o desempenho acústico. Este artigo tem como objetivo avaliar o custo para o atendimento de cada um dos três níveis de desempenho abordados pela norma (mínimo, intermediário e superior) para o sistema de vedações verticais e o sistema de pisos. Foram determinadas soluções para o atendimento dos níveis e, em seguida os custos foram estimados, estimados os custos. Entre as soluções para os sistemas de vedações verticais internas, foram analisados dois tipos de materiais: alvenaria e placas de drywall, também avaliados entre si. Os resultados obtidos mostraram um menor custo na solução adotada para o nível superior de desempenho, seguido do nível mínimo e, por fim, o intermediário. Como considerações finais, o menor custo do nível superior dado em acordo com o tipo de laje adotada na camada devido ao tipo de laje adotado na camada estrutural do sistema de pisos ser mais eficiente na redução sonora, porém possuir menor custo. Analisando apenas o sistema de vedações verticais, o aumento de custo seguiu o aumento de eficiência acústica, e a adoção de placas de drywall se mostrou mais econômica que a alvenaria.

Palavras-chave: Norma de desempenho. Desempenho acústico. Vedações verticais. Sistemas de pisos.

\section{ABSTRACT}

With the entry into force of NBR 15575 (ABNT, 2013), the performance of buildings has become more prominent in the civil construction sector. Among the demands

1 Engenheira Civil pela Pontifícia Universidade Católica do Rio Grande do Sul (PUCRS). E-mail: analeticiaspode@gmail.com 2 Doutor em Construção Civil pela Universidade Federal do Rio Grande do Sul (NORIE/UFRGS). Docente da Fundação Universidade Regional de Blumenau (FURB) e da Pontifícia Universidade Católica do Rio Grande do Sul (PUCRS). E-mail: arohden@furb.br

\section{INTER/SCIENTIA}

REVISTA INTERSCIENTIA | V. 7 | N. 2 | P. 4-26 | JUL-DEZ/2019 
brought by the performance standard is the acoustic performance. The objective of this article is to evaluate the cost of attending to each of the three levels of performance covered by the standard (minimum, intermediate and superior) for the vertical fence system and the floor system. Solutions were determined to meet the levels, and then costs were estimated, estimated costs. Among the solutions for the systems of internal vertical seals, two types of materials were analyzed: masonry and drywall boards, also evaluated among themselves. The results obtained showed a lower cost in the solution adopted for the higher level of performance, followed by the minimum level and finally the intermediate. As final considerations, the lower cost of the upper level given in agreement with the type of slab adopted in the layer due to the type of slab adopted in the structural layer of the floor system is more efficient in the sound reduction, but has a lower cost. Analyzing only the vertical fence system, the cost increase followed the increase in acoustic efficiency, and the adoption of drywall boards proved to be more economical than masonry.

Keywords: Performance standard. Acoustic performance. Vertical fences. Floor systems.

\section{INTRODUÇÃO}

O desempenho de edificações é estudado e abordado internacionalmente desde a segunda metade do século passado (BORGES, 2008). O conceito de desempenho consiste no comportamento dos sistemas construtivos quando são submetidos a condições reais de uso e exposição. Conforme Gibson (1982 apud BORGES, 2008, p.28): "A preocupação é com os requisitos que a construção deve atender e não com a prescrição de como ela deve ser construída". Um grande marco nesta abordagem foi a elaboração da ISO 6241 (ISO, 1984), trazendo uma listagem de padrões a ser considerados pelos usuários das edificações (BORGES, 2008).

Conforme Cordovil (2013), o desempenho foi estudado no Brasil desde a década de setenta, porém a abordagem da qualidade no país não evoluiu rapidamente como a nível internacional. Borges (2008) destacou o grande crescimento da construção civil no país e a importância da exigência de um desempenho mínimo nas construções. Em 2008, então, foi publicada a primeira versão da Norma de Desempenho, porém entrou em vigor apenas depois de cinco anos (2013), após ser revisada e republicada (CORDOVIL, 2013).

Ao avaliar o desempenho dos sistemas construtivos, a NBR 15575 (ABNT, 2013) representa uma grande evolução no setor da construção civil do Brasil (CBIC, 2013). As exigências abordadas na Norma de Desempenho são quanto aos sistemas estruturais, de pisos, de vedações verticais internas e externas, de coberturas e o 
hidrossanitário. São três os níveis de desempenho estabelecidos pela Norma: Mínimo (M), Intermediário (I) e Superior (S).

O desempenho acústico é uma da das exigências que a Norma de Desempenho traz. Conforme Rezende et al. (2014), com o crescimento dos espaços urbanos e o alto índice de veículos nas ruas, bem como as demais fontes ruídos, sendo necessária a expansão do isolamento sonoro. Os níveis acústicos considerados em norma são quanto aos ruídos aéreos provenientes do exterior da edificação habitacional e ao isolamento acústico entre áreas comuns e privativas.

Este trabalho tem como foco avaliar o custo de uma edificação quando ela atenda cada os três níveis de desempenho acústico para vedações verticais externas, vedações verticais internas e sistema de pisos, conforme especificações da NBR 15575 (ABNT, 2013). Serão usadas soluções para os três níveis de desempenho de cada sistema construtivo, sendo que para as vedações verticais internas haverá a determinação para dois tipos de materiais, sendo eles: alvenaria de vedação e drywall. Após determinadas as soluções, será feito o comparativo de custos e uma avaliação dos resultados.

Este trabalho aborda apenas o desempenho acústico da edificação, não sendo levado em conta qualquer outro desempenho abordado em norma. As informações contidas neste trabalho foram delimitadas apenas a referências bibliográficas de natureza exploratória e informações de fornecedores.

\section{DESEMPENHO ACÚSTICO DE EDIFICAÇÕES}

O desempenho acústico das edificações é um fator de grandes reclamações dos usuários, principalmente em habitações coletivas (condomínios verticais ou horizontais), onde não se há controle sobre os ruídos provocados por vizinhos (SINDUSCON, 2015). Conforme Rezende et al. (2014), nos últimos anos, devido ao crescimento do setor da construção civil, existe a necessidade de tornar ágil os processos construtivos sem causar impactos nos custos das obras. Como solução adotada surgem alguns fatores de qualidade foram deixados em segundo plano, sendo o caso da qualidade acústica.

Com a publicação da NBR 15575 (ABNT, 2013) houve um grande avanço para a construção civil, a partir de sua obrigatoriedade, níveis considerados mínimos de desempenho deveriam ser respeitados pelos construtores, que passaram a precisar alinhar requisitos da norma a outros fatores mais valorizados pelo mercado.

Além dos níveis mínimos, a Norma de Desempenho traz também níveis intermediários e superiores de desempenho. Apesar de não haver obrigatoriedade para o atendimento destes últimos níveis citados, eles são parâmetros para que as edificações possam ser classificadas conforme seu nível de desempenho, e com o atendimento destes maiores níveis de desempenho, a categoria das edificações pode ser elevada. O atendimento ou superação dos níveis intermediário e superior 
passou a poder ser utilizado pelas construtoras como um grande instrumento de marketing, considerando que o melhor desempenho pode gerar um custo extra (REZENDE et al., 2014).

Conforme Michalski (2011), a redução da transmissão de energia sonora entre dois ambientes é uma solução para a obtenção da melhora no desempenho acústico, podendo ser feita através do isolamento sonoro nas vedações verticais e horizontais. O Desempenho é estabelecido com a definição de requisitos, critérios e métodos de avaliação, o que torna a compreensão de seu cumprimento mais acessível (ABNT, 2013), facilitando o atendimento dos requisitos propostos.

\subsection{CRITÉRIOS DO DESEMPENHO ACÚSTICO DO SISTEMA DE PISOS}

Conforme o conceito abordado na NBR 15575-3 (ABNT, 2013, p.4), um sistema de pisos se trata de um "sistema horizontal ou inclinado composto por um conjunto parcial ou total de camadas [...] destinado a cumprir a função de estrutura, vedação e tráfego, conforme os critérios definidos nesta Norma". O sistema de pisos tem como uma de suas funções, proporcionar o isolamento acústico, tanto entre unidades distintas, quanto entre diferentes recintos de uma mesma unidade (MICHALSKI, 2011). O desempenho acústico deste sistema é tratado na parte 3 da Norma de Desempenho, a qual apresenta os requisitos e critérios para a verificação do isolamento acústico do sistema de piso entre unidades autônomas.

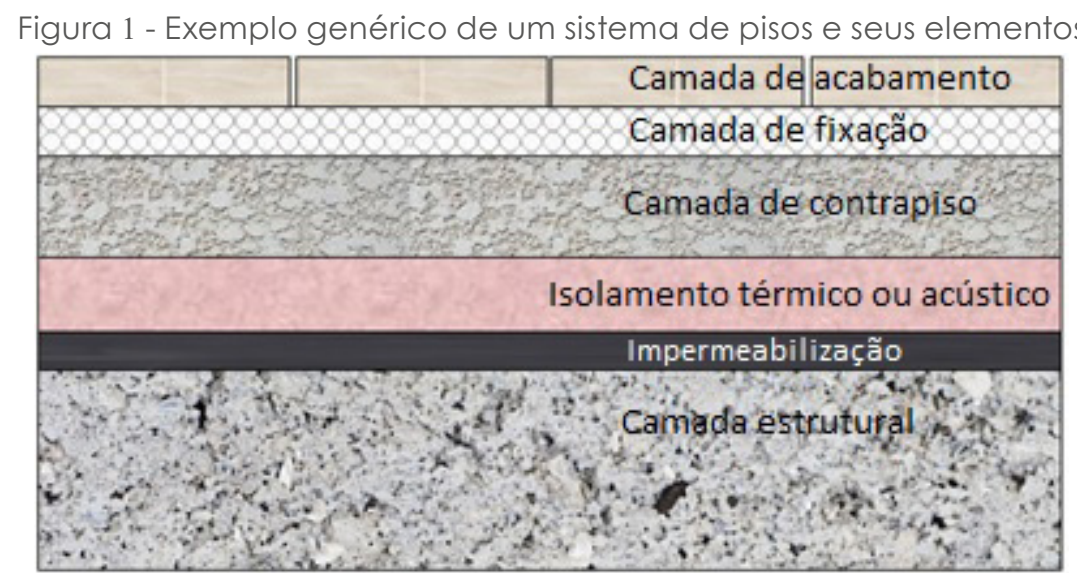

Fonte: Adaptado por autores de ABNT (2013)

Conforme a NBR 15575-3 (ABNT, 2013), a avaliação do desempenho acústico do sistema de pisos considera o isolamento de ruído de impacto e isolamento de ruído aéreo. O ruído de impacto é transmitido através de corpos sólidos, e pode ser causado, por exemplo, pelo caminhamento ou queda de objetos, já o ruído aéreo é transmitido através do ar, como conversas, músicas, entre outros (CARVALHO, 2006). Os parâmetros analisados para a avaliação do desempenho acústico são, para o ruído de impacto e o ruído aéreo, respectivamente: nível de pressão sonora

\section{INTER SCIENTIA}

REVISTA INTERSCIENTIA | V. 7 | N. 2 | P. 4-26 | JUL-DEZ/2019 
de impacto padrão ponderado ( $L_{n T, w}$ ) e diferença padronizada de nível ponderada $\left(D_{n T, w}\right)$.

Os níveis de pressão sonora de impacto diferem nas unidades habitacionais autônomas posicionadas em pavimentos distintas e para áreas de uso coletivo sobre unidades habitacionais autônomas. Na tabela 1 estão descritos todos os níveis de desempenho para ambos os elementos, com seus respectivos níveis de pressão sonora de impacto.

Para a análise da diferença padronizada de nível ponderada, são considerados três elementos, pois quando um dos recintos da unidade habitacional seja dormitório, ele possui valor diferenciado. Na tabela 2 estão descritos todos os níveis de desempenho para todos os elementos, com suas respectivas diferenças padronizada de nível ponderada.

Tabela 1 - Critério e nível de pressão sonora de impacto padrão ponderado, $\mathrm{L}_{\mathrm{nT}, \mathrm{w}, \mathrm{W}}$

\begin{tabular}{|c|c|c|}
\hline Elemento & $\mathrm{L}_{\mathrm{nT,w}}^{\prime}[\mathrm{dB}]$ & $\begin{array}{l}\text { Nível de } \\
\text { desempenho }\end{array}$ \\
\hline \multirow{3}{*}{$\begin{array}{c}\text { Sistema de piso separando unidades habitacionais autônomas } \\
\text { posicionadas em pavimentos distintos }\end{array}$} & 66 a 80 & $M$ \\
\hline & 56 a 65 & I \\
\hline & $\leq 55$ & $S$ \\
\hline \multirow{3}{*}{$\begin{array}{c}\text { Sistema de piso de áreas de uso coletivo (atividades de lazer e } \\
\text { esportivas, como home theater, salas de ginástica, salã de destas, } \\
\text { salâo de jogos, banheiros e vestiários coletivos, cozinhas e lavanderias } \\
\text { coletivas) sobre unidades habitacionais autônomas }\end{array}$} & 51 a 55 & M \\
\hline & 46 a 50 & I \\
\hline & $\leq 45$ & $S$ \\
\hline
\end{tabular}

Fonte: ABNT (2013)

Tabela 2 - Critérios de diferença padronizada de nível ponderada, $\mathrm{D}_{\mathrm{nT}, \mathrm{w}}$

\begin{tabular}{|c|c|c|}
\hline Elemento & $D_{n T, w}[d B]$ & $\begin{array}{c}\text { Nível de } \\
\text { desempenho }\end{array}$ \\
\hline \multirow{3}{*}{$\begin{array}{c}\text { Sistema de piso separando unidades habitacionais autônomas de } \\
\text { áreas em que um dos recintos seja dormitório }\end{array}$} & 45 a 49 & $M$ \\
\hline & 50 a 54 & I \\
\hline & $\geq 55$ & $S$ \\
\hline \multirow{3}{*}{$\begin{array}{c}\text { Sistema de piso separando unidades habitacionais autônomas de } \\
\text { áreas comuns de transito eventual, como corredores e escadaria nos } \\
\text { pavimentos, bem como em pavimentos distintos }\end{array}$} & 40 a 44 & $M$ \\
\hline & 45 a 49 & I \\
\hline & $\geq 50$ & S \\
\hline \multirow{3}{*}{$\begin{array}{l}\text { Sistema de piso separando unidades habitacionais autônomas de } \\
\text { áreas comuns de uso coletivo, para atividades de lazer e esportivas, } \\
\text { como home theater, salas de ginástica, salão de festas, salão de } \\
\text { jogos, banheiros e vestiários colefivos, cozinhas e lavanderias coletivas }\end{array}$} & 45 a 49 & $M$ \\
\hline & 50 a 54 & I \\
\hline & $\geq 55$ & $S$ \\
\hline
\end{tabular}

Fonte: ABNT (2013) 


\subsection{CRITÉRIOS DE DESEMPENHO ACÚSTICO DE SISTEMAS DE VEDAÇÕES VERTICAIS}

Sistemas de vedações verticais internas e externas (SVVIE) é definido como, conforme NBR 15575-4 (ABNT, 2013, p.4), "partes da edificação habitacional que limitam verticalmente a edificação e seus ambientes, como as fachadas e as paredes ou divisórias internas". Mishalski (2011) destaca que estas vedações exercem, como uma de suas funções, o isolamento sonoro, tanto entre os meios externos e internos, como entre unidades distintas e entre recintos de uma mesma unidade. O desempenho acústico de vedações verticais é tratado na parte 4 da NBR 15575 (ABNT, 2013), sendo apresentados os critérios e requisitos para o isolamento acústico entre unidades autônomas e entre o meio externo e interno da edificação.

Os parâmentros observados na norma para a verificação do desempenho acústico das vedações verticais são três: diferença padronizada de nível ponderada $\left(D_{n T, w}\right)$; diferença padronizada de nível ponderada a 2 metros de distância da fachada $\left(D_{2 m, n T, w}\right)$ e índice de redução sonora ponderado $\left(R_{w}\right)$. O índice de redução sonora ponderado é o único ensaiado em laboratório, sendo o parâmetro considerado a nível de projeto.

As vedações externas (fachadas) possuem um índice de redução sonora ponderado conforme a intensidade de fonte de ruído sofrida pela habitação. São três classes de ruído: classe l; classe II e classe III, quanto maior o numeral romano, maior a fonte de ruído. Na tabela 3 estão apresentados todos os índices de redução sonora ponderado requisitados pela norma, conforme classe e nível de desempenho.

Tabela 3 - Índice de redução sonora ponderado, $\mathrm{R}_{\mathrm{w}^{\prime}}$ de fachadas

\begin{tabular}{|c|c|c|c|}
\hline Classe de Ruído & Localização da habitação & $R_{w}[d B]$ & $\begin{array}{c}\text { Nível de } \\
\text { desempenho }\end{array}$ \\
\hline \multirow{3}{*}{ I } & \multirow{3}{*}{$\begin{array}{l}\text { Habitação localizada distante de fontes de } \\
\text { ruído intenso }\end{array}$} & $\geq 25$ & $M$ \\
\hline & & $\geq 30$ & I \\
\hline & & $\geq 35$ & $S$ \\
\hline \multirow{3}{*}{ II } & \multirow{3}{*}{$\begin{array}{c}\text { Habitação localizada em áreas sujeitas a } \\
\text { situações de ruído não enquadráveis nas classes } \\
\text { I e III }\end{array}$} & $\geq 30$ & $M$ \\
\hline & & $\geq 35$ & I \\
\hline & & $\geq 40$ & $S$ \\
\hline \multirow{3}{*}{ III } & \multirow{3}{*}{$\begin{array}{c}\text { Habitação sujeita a ruído intenso de meios de } \\
\text { transporte e de outras naturezas, desde que } \\
\text { conforme a legislação }\end{array}$} & $\geq 35$ & $M$ \\
\hline & & $\geq 40$ & I \\
\hline & & $\geq 45$ & $S$ \\
\hline
\end{tabular}

Fonte: ABNT (2013)

As vedações internas (vedações entre ambientes) são divididas em seis elementos, classificados conforme os ambientes os quais elas dividem. Na tabela 4 estão descritos os níveis de desempenho para cada elemento, com seus respectivos índices de redução ponderada.

\section{INTER/SCIENTIA}

REVISTA INTERSCIENTIA | V. 7 | N. 2 | P. 4-26 | JUL-DEZ/2019 
Tabela 4 - Índice de redução sonora ponderado, $\mathrm{R}_{w^{\prime}}$ de componentes construtivos utilizados nas vedações entre ambientes

\begin{tabular}{|c|c|c|}
\hline Elementos & $R_{w}[d B]$ & $\begin{array}{c}\text { Nível de } \\
\text { desempenho }\end{array}$ \\
\hline \multirow{3}{*}{$\begin{array}{l}\text { Parede entre unidades habitacionais autônomas (paredes de } \\
\text { geminação), nas situaçôes onde não haja ambiente dormitório }\end{array}$} & 45 a 49 & $M$ \\
\hline & 50 a 54 & I \\
\hline & $\geq 55$ & S \\
\hline \multirow{3}{*}{$\begin{array}{l}\text { Parede entre unidades habitacionais autônomas (parede de } \\
\text { geminação), caso pelo menos um dos ambientes seja dormitório }\end{array}$} & 50 a 54 & $M$ \\
\hline & 55 a 59 & I \\
\hline & $\geq 60$ & $S$ \\
\hline \multirow{3}{*}{$\begin{array}{c}\text { Parede cega de dormitórios entre uma unidade habitacional e áreas } \\
\text { comuns de trânsito eventual, como corredores e escadaria nos } \\
\text { pavimentos }\end{array}$} & 45 a 49 & $M$ \\
\hline & 50 a 54 & I \\
\hline & $\geq 55$ & $S$ \\
\hline \multirow{3}{*}{$\begin{array}{c}\text { Parede cega de salas e cozinhas entre uma unidade habitacional e } \\
\text { áreas comuns de trânsito eventual como corredores e escadaria dos } \\
\text { pavimentos }\end{array}$} & 35 a 39 & $M$ \\
\hline & 40 a 44 & I \\
\hline & $\geq 45$ & S \\
\hline \multirow{3}{*}{$\begin{array}{c}\text { Parede cega entre uma unidade habitacional e áreas comuns de } \\
\text { permanência de pessoas, atividades de lazer e atividades esportivas, } \\
\text { como home theater, salas de ginástica, saläo de festas, saläo de jogos, } \\
\text { banheiros e vestiários coletivos, cozinhas e lavanderias coletivas }\end{array}$} & 50 a 54 & $M$ \\
\hline & 55 a 59 & I \\
\hline & $\geq 60$ & $S$ \\
\hline \multirow{3}{*}{ Conjunto de paredes e portas de unidades distintas separadas pelo hall } & 45 a 49 & M \\
\hline & 50 a 54 & I \\
\hline & $\geq 55$ & S \\
\hline
\end{tabular}

Fonte: ABNT (2013)

\subsubsection{INFLUÊNCIA DAS ESQUADRIAS NO DESEMPENHO ACÚSTICO DE VEDAÇÕES VERTICAIS}

Sendo um dos principais componentes que forma uma construção, as esquadrias possuem um papel fundamental papel fundamental no desempenho das edificações, influenciando diretamente do desempenho dos SVVIE. No caso do desempenho acústico, elas podem intensificar o acesso de ruídos, principalmente com a ocorrências de uma fabricação ou instalação inadequada, causando grande desconforto (LIMA, 2017).

Para a verificação do desempenho acústico das vedações verticais, também é necessário seguir critérios e requisitos conforme a NBR 10821 (ABNT, 2017), norma que aborda sobre esquadrias para edificações. Esta norma classifica o nível de desempenho das esquadrias individualmente, como pode-se ver na tabela 5, não levando em conta o resto do sistema, porém, o sistema ele deve ser avaliado como um todo. Para a avaliação conjunta do desempenho acústico dos SVVIE. 
Tabela 5 - Níveis de desempenho das esquadrias

\begin{tabular}{ccccc}
\hline Ensaio & \multicolumn{4}{c}{ Desempenho } \\
& D & C & B & A \\
\hline $\begin{array}{c}\text { Índice de redução sonora ponderado } R_{w} \\
\text { (dB) }\end{array}$ & $R_{w}<18$ & $18 \leq R_{w}<24$ & $24 \leq R_{w}<30$ & $R_{w} \geq 30$ \\
\hline
\end{tabular}

Fonte: ABNT (2017)

\subsection{REFERENCIAL DE ATUALIZAÇÃO}

Mesmo antes da publicação da NBR 15575 (ABNT, 2013), já era falado sobre o conforto acústico das edificações. Polli e Viveiros (2007) fizeram uma análise da relação entre o custo dos imóveis e o conforto acústico deles. Na ocasião, foi comparado o isolamento acústico conforme o padrão das edificações, que considerou padrão de acabamento e de investimento, sendo as mesmas divididas em: alto padrão (AP), médio padrão (MP), baixo padrão (BP) e padrão popular (PP). A tendência do mercado é que o padrão das edificações seja influenciado pelo seu desempenho, quanto maior o padrão, maior o benefício proporcionado, porém na análise feita por Polli e Viveiros (2007), não havia grandes diferenças quanto ao isolamento acústico das edificações, sendo o $R_{w}$ médio de 38,6 decibéis, que foi comparado com $50 \mathrm{~dB}$ propostos por normas internacionais, demostrando que o desempenho era insuficiente para atender um conforto acústico mínimo mesmo em edificações de alto padrão. Se comparado com os valores da norma de desempenho, ainda não publicada, não atendendo o nível mínimo de desempenho.

Nienkoetter et al. (2014) fizeram uma análise no impacto que o tratamento acústico de lajes causa no custo de edificações residenciais. Foram analisados oito projetos padrão considerados conforme a NBR 12721 (ABNT, 2006), e para cada projeto, oito materiais diferentes como isolante acústico no sistema de pisos, todos atendem à NBR 15575 (ABNT, 2013). A conclusão foi que soluções acústicas têm baixo impacto no valor final do empreendimento, mas é possível perceber que o custo tem influência conforme o padrão do empreendimento, o impacto é maior em empreendimentos de padrão mais baixo.

Coelho (2017) abordou o impacto no custo de uma edificação para que ela atingisse os três níveis de desempenho propostos na NBR 15575 (ABNT, 2013). Para a conclusão do artigo, foram elaborados projetos de vedações verticais que atendessem os níveis mínimo, intermediário e superior, e a partir deles as composições orçamentárias. A comparação foi produzida considerando paredes externas de blocos cerâmicos e duas opções de paredes internas (blocos cerâmicos e drywall). Na conclusão, Coelho (2017) observou uma pequena vantagem no uso de blocos cerâmicos em toda a edificação, e, a respeito do desempenho acústico, foi observado que a diferença é mais significativa, chegando a um aumento de aproximadamente $10 \%$ para o atendimento do nível intermediário em comparação 
com o nível mínimo de desempenho, e de mais de $20 \%$ para atender ao nível superior.

\section{MATERIAIS E MÉTODOS}

\subsection{MATERIAIS}

Para o desenvolvimento do artigo foi utilizada a análise de um empreendimento localizado na cidade de Gravataí/RS, o qual contempla oito apartamentos por pavimento, todos com dois dormitórios, um banheiro social, uma sala de estar/jantar e uma cozinha, sendo metade destes apartamentos com área de $56,06 \mathrm{~m}^{2}$ e o restante de $55,72 \mathrm{~m}^{2}$.

Figura 2 - Planta baixa do pavimento tipo

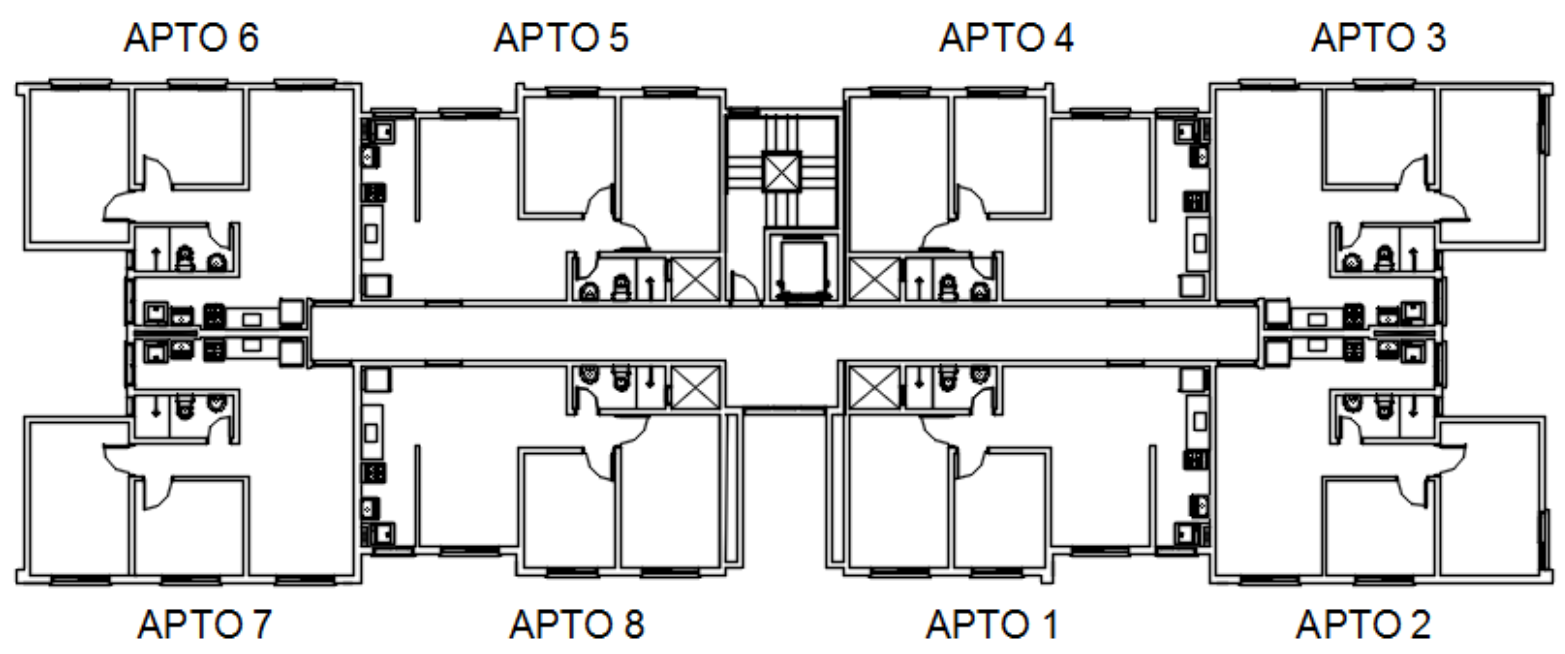

Fonte: os autores (2019)

\subsection{MÉTODOS}

A metodologia utilizada neste trabalho está resumida na Figura 3. Posteriormente, cada uma das etapas será explicada mais detalhadamente.

Figura 3 - Etapas do trabalho

Classificação das

divisórias do

projeto conforme

exigencias da NBR 15575
Levantamento

dos materiais

necessários para

atendimento dos

niveis $M_{r}$ I e S de

desempenho
Análise dos

resultados

(custos) obtidos

em função do

nível de

desempenho

Fonte: os autores (2019) 


\subsubsection{CLASSIFICAÇÃO DAS DIVISÓRIAS DO PROJETO}

As vedações horizontais (sistemas de pisos) e vedações verticais foram classificadas seguindo especificações trazidas na NBR 15575 (ABNT, 2013) e já revisadas neste trabalho. As especificações e materiais escolhidos podem ser melhor entendidos nos próximos itens. Porém, antes, para melhor visualização, as vedações verticais internas e externas foram destacadas conforme cores apresentadas na figura 4 e podem ser acompanhadas em seguida nas figuras 5, 6, 7 e 8 .

Figura 4 - Classificação das vedações verticais

1 Parede entre unidades habitacionais autônomas (paredes de geminação), nas situaçốes onde não haja ambiente dormitório.

2 Parede entre unidades habitacionais autônomas (parede de geminação), caso pelo menos um dos ambientes seja dormitório.

3 Parede cega de dormitórios entre uma unidade habitacional e áreas comuns de trânsito eventual, como corredores e escadaria nos pavimentos.

4 Parede cega de salas e cozinhas entre uma unidade habitacional e áreas comuns de trânsito eventual como corredores e escadaria dos pavimentos.

Parede cega entre uma unidade habitacional e áreas comuns de permanência de pessoas, atividades de lazer e atividades esportivas.

6 Conjunto de paredes e portas de unidades distintas separadas pelo hall.

7) Paredes Externas nas situações onde o ambiente interno seja dormitório.

Paredes sem exigências na NBR 15575

Fonte: adaptado de NBR 15575 (ABNT, 2013)

$\mathrm{Na}$ figura 5 temos os apartamentos 1 e 2 com as vedações verticais categorizadas conforme as exigências da NBR 15575 (ABNT, 2013) e destacadas conforme figura 4 . 
Figura 5 - Classificação das vedações verticias dos apartamentos 1 e 2

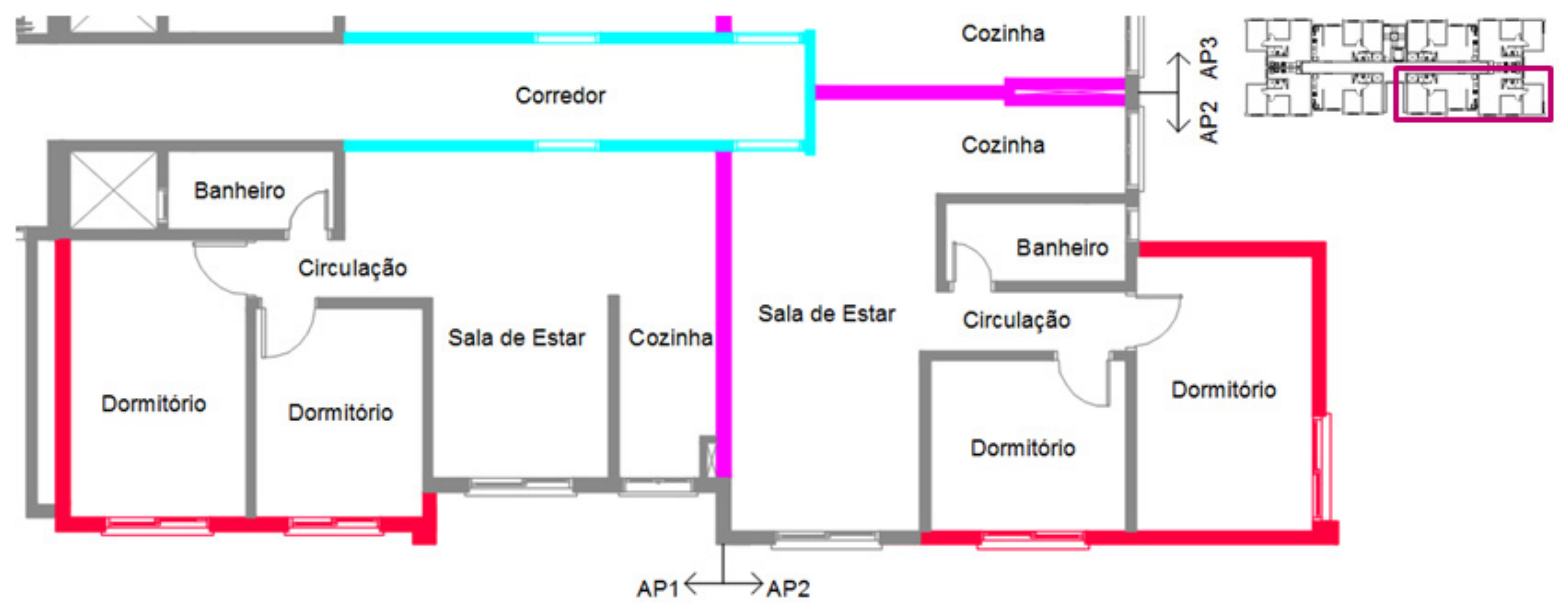

Fonte: os autores (2019)

Na figura 6 temos, classificados nas mesmas condições da figura anterior, os apartamentos 4 e 3 .

Figura 6 - Classificação das vedações verticais dos apartamentos 4 e 3

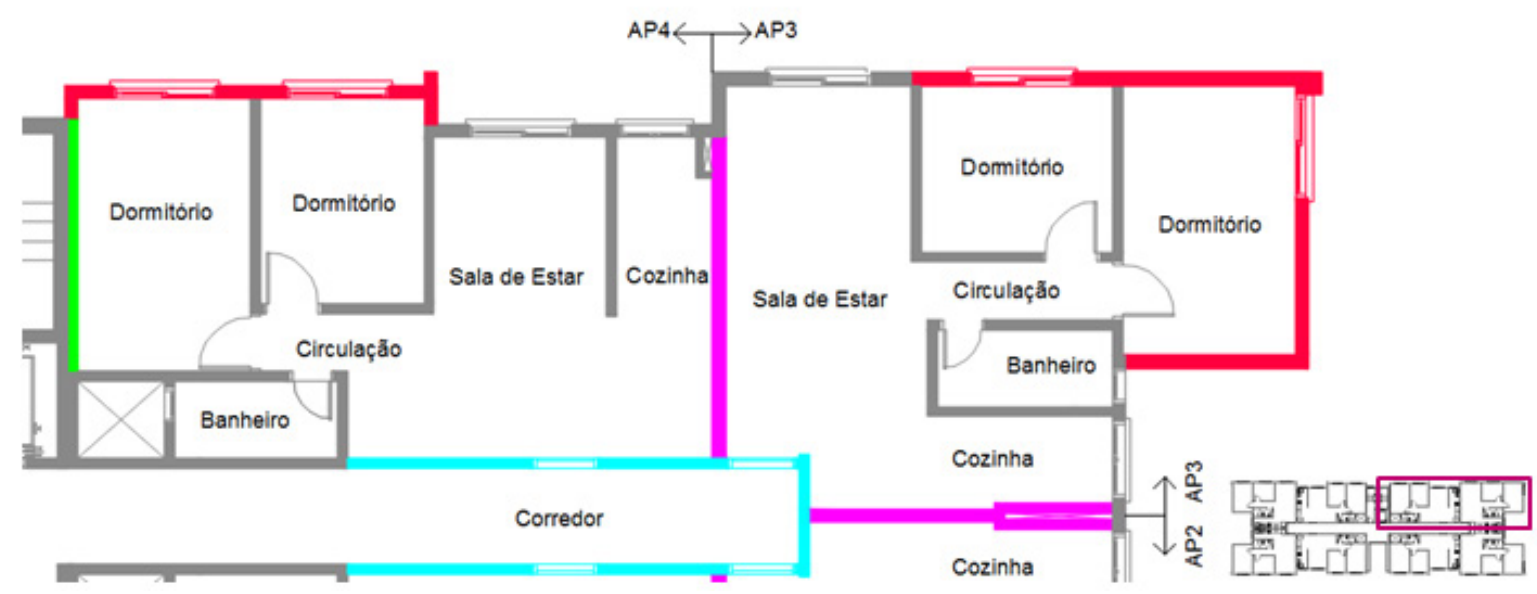

Fonte: os autores (2019)

Na figura 7, os apartamentos 6 e 5. 
Figura 7 - Classificação das vedações verticais dos apartamentos 6 e 5

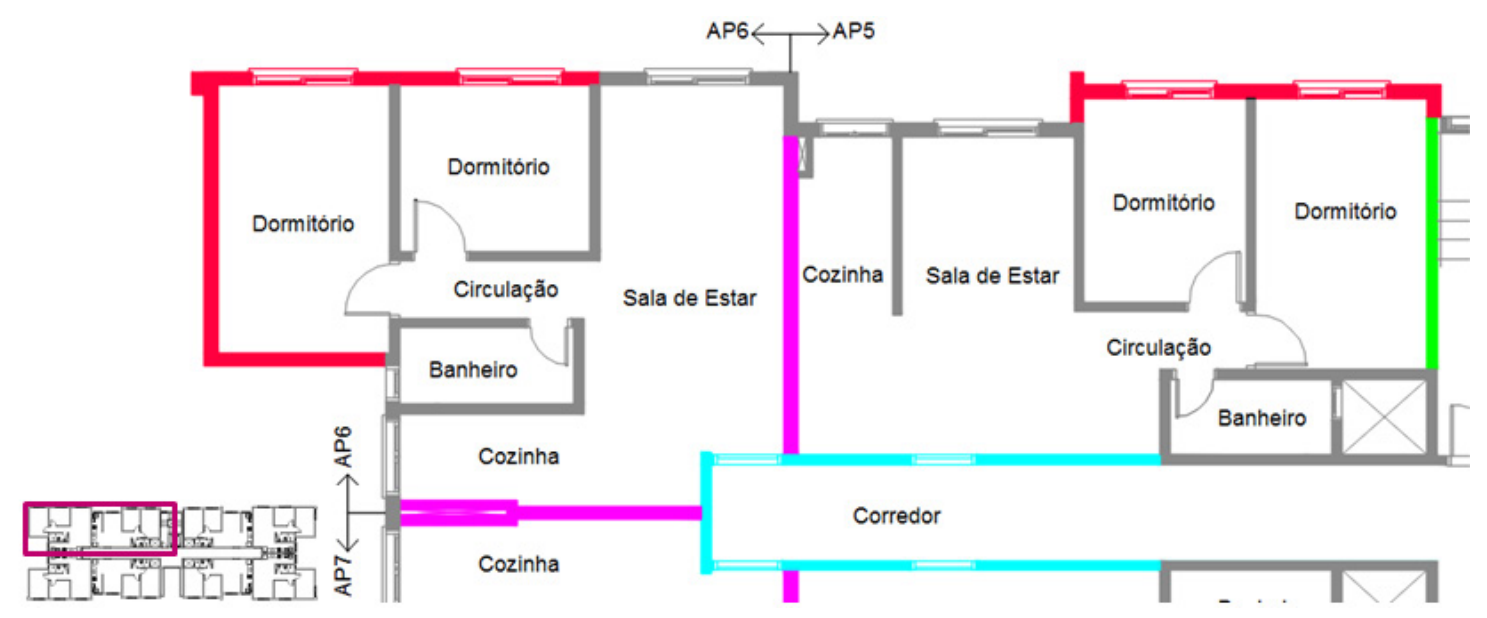

Fonte: os autores (2019)

Por fim, temos os apartamentos 7 e 8 na figura 8

Figura 8 - Classificação das vedações verticais dos apartamentos 7 e 8

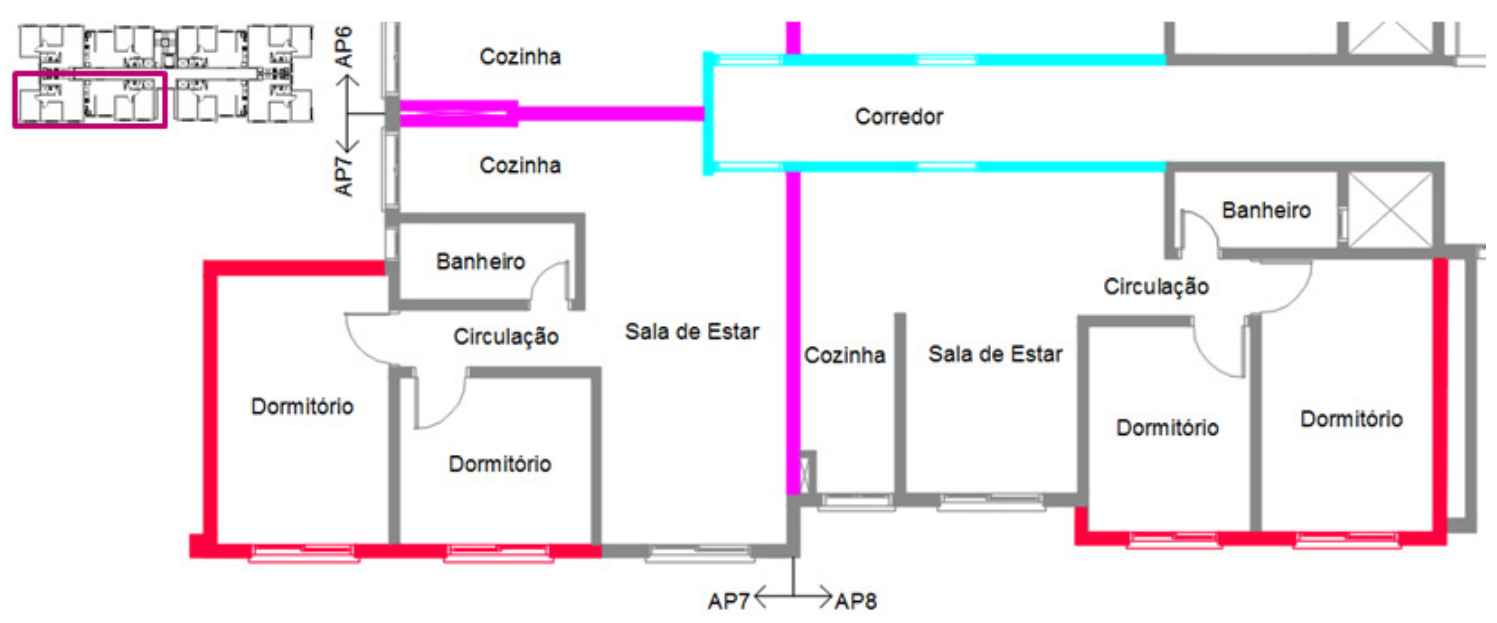

Fonte: os autores (2019)

\subsubsection{Classificação dos sistemas de pisos}

No projeto estudado, o edifício possui todos os pavimentos com igual configuração, sendo todos apenas com unidades habitacionais, então todas unidades autônomas são posicionadas sobre outra unidade autônoma. Para agilização do projeto e execução, foi definido que todo o sistema de piso do pavimento terá igual configuração, atendendo sempre a situação mais crítica dele, com exceção das áreas molhadas, que serão revestidas em todos os casos com porcelanato. 
A definição da escolha da configuração mais adequada pode ser feita a partir do estudo realizado por Nunes et al. (2014) e definida na Tabela 6, juntamente com os níveis de desempenho atingidos e seus níveis de pressão sonora de impacto e diferenças padronizadas de nível ponderada.

Tabela 6 - Configuração dos sistemas de piso conforme nível de desempenho atingido

\begin{tabular}{|c|c|c|c|c|}
\hline $\begin{array}{c}\text { Nível de } \\
\text { Desempenho }\end{array}$ & Configuração do sistema de Pisos & $\begin{array}{l}\mathrm{L}^{\prime} \\
{[\mathrm{dBT}]}\end{array}$ & $\begin{array}{l}D_{n T w} \\
{[d B]}\end{array}$ & $\begin{array}{l}\text { Custo } \\
(\mathrm{R} \$) / \mathrm{m}^{2}\end{array}$ \\
\hline M & $\begin{array}{l}\text { Concreto maciço } 10 \mathrm{~cm}+\text { Contrapiso de } \\
\text { argamassa comum } 5 \mathrm{~cm}+\text { laminado de madeira } \\
7 \mathrm{~mm} \text { com manta de polietileno expandido } 2 \mathrm{~mm}\end{array}$ & 56 & 48 & 404,02 \\
\hline 1 & $\begin{array}{c}\text { Concreto maciço } 10 \mathrm{~cm}+\text { Contrapiso de } \\
\text { argamassa comum } 5 \mathrm{~cm}+\text { laminado de madeira } \\
7 \mathrm{~mm} \text {, com manta de fibras de polipropileno } \\
5 \mathrm{~mm}\end{array}$ & 54 & 53 & 436,79 \\
\hline$S$ & $\begin{array}{c}\text { Laje nervurada com cubetas de EPS }+ \\
\text { Contrapiso de argamassa com brita leve } 5 \mathrm{~cm} \\
\text { (1:1:4) e argamassa comum } 2 \mathrm{~cm}+\text { laminado de } \\
\text { madeira } 7 \mathrm{~mm}\end{array}$ & 50 & 55 & 329,87 \\
\hline
\end{tabular}

Fonte: adaptados por autores (2019) de Nunes et al. (2014).

\subsubsection{Classificação das vedações verticais externas}

Para a definição das vedações verticais externas, foi concluído que classe de ruído onde a habitação está localizada é a classe II. Conforme NBR 15575 (2013), para classificação das vedações externas, deve-se avaliar os dormitórios das unidades habitacionais, e, conforme CBIC (2017), o que determina o desempenho do SVVE é o alinhamento da capacidade de isolamento da parede e da capacidade de isolamento e condições de instalação da esquadria.

A fim de padronizar a edificação, foi determinada a relação entre a superfície da parede e esquadria mais desfavorável entre todos os dormitórios do pavimento. A partir desta relação mais desfavorável, sendo que a configuração da parede foi adotada a mesma para os três níveis de desempenho, foi calculado o índice de redução sonora ponderado das esquadrias $\left(R_{e}\right)$. Os resultados obtidos estão apresentados na tabela 7.

Tabela 7 - Índice de redução sonora ponderado das esquadrias

\begin{tabular}{ccccccc}
\hline Nível de Desempenho & $\mathbf{R}_{\mathrm{w}}(\mathrm{dB})$ & $\mathbf{R}_{\mathrm{p}}(\mathrm{dB})$ & $\mathbf{S}_{\mathrm{p}}\left(\mathbf{m}^{2}\right)$ & $\mathbf{S}_{\mathrm{e}}\left(\mathbf{m}^{2}\right)$ & $\mathbf{S}_{\mathrm{f}}\left(\mathbf{m}^{2}\right)$ & $\mathbf{R}_{\mathrm{e}}(\mathrm{dB})$ \\
\hline $\mathrm{M}$ & 30 & 45 & 6,19 & 1,44 & 7,63 & 23 \\
\hline $\mathrm{I}$ & 35 & 45 & 6,19 & 1,44 & 7,63 & 28 \\
\hline $\mathrm{S}$ & 40 & 45 & 6,19 & 1,44 & 7,63 & 34 \\
\hline
\end{tabular}

Fonte: autores (2019) 
A configuração das paredes externas para todos os níveis de desempenho é com blocos cerâmicos de vedação $14 \times 19 \times 29$ e $3 \mathrm{~cm}$ de reboco nas faces externa e interna, sendo a espessura total da parede de $20 \mathrm{~cm}$ e $R_{p}$ de $45 \mathrm{~dB}$, conforme manual de desempenho de sistemas de alvenaria com blocos cerâmicos Pauluzzi (2017).

Tendo os valores mínimos de Re para atendimento dos níveis $M$, I e $S$, as esquadrias foram escolhidas a partir de informações da empresa Kasper Esquadrias, a qual forneceu também os valores do produto. Os valores apresentados na tabela 8 são referentes ao custo das janelas instaladas.

Tabela 8 - Especificações das esquadrias adotadas para os níveis de desempenho M, I e S

\begin{tabular}{|c|c|c|c|}
\hline Especificações das Esquadrias de PVC & $R_{w}(d B)$ & $\begin{array}{c}\text { Nível de } \\
\text { Desempenho }\end{array}$ & $\begin{array}{l}\text { Custo } \\
(\mathrm{RS}) / \text { un }\end{array}$ \\
\hline $\begin{array}{c}\text { Janela PVC de correr } 2 \text { folhas com escovas de vedação e } \\
\text { vidro duplo laminado de } 20 \mathrm{~mm}\end{array}$ & 23 & $M$ & $R \$ 2559,98$ \\
\hline $\begin{array}{c}\text { Janela PVC Maxim ar com escovas de vedação, borrachas } \\
\text { com EPDM e vidro duplo laminado de } 24 \mathrm{~mm}\end{array}$ & 28 & I & $R \$ 3149,98$ \\
\hline $\begin{array}{l}\text { Janela PVC Oscilo-batente com borrachas em EPDM, } \\
\text { maçanetas multipontos e vidro duplo laminado de } 28 \mathrm{~mm}\end{array}$ & 37 & S & $R \$ 3629,98$ \\
\hline
\end{tabular}

Fonte: adaptados por autores (2019) de CBIC (2017) e SINAPI (2018)

\subsubsection{Classificação das vedações verticais internas}

As vedações verticais internas foram classificadas conforme as situações em que estão posicionadas, seguindo os critérios da Tabela 4. Conforme abordado pela Associação Brasileira do Drywall (2015), existem duas maneiras de reduzir a transmissão de sons entre ambientes. As opções seriam utilizando-se materiais de alta densidade ou um sistema massa-mola-massa. Logo, duas opções de divisórias internas foram analisadas neste trabalho, alvenaria e drywall, as quais serão apresentadas a seguir.

\subsection{Divisórias de Alvenaria}

Stradiotto (2016) constatou que a presença de reboco de espessura causa aumento significativo no índice de redução sonora ponderado em paredes de alvenaria, devido ao aumento da densidade superficial do sistema. Para a determinação da configuração das divisórias internas de alvenaria, foi utilizado como referência o manual de desempenho de sistemas de alvenaria com blocos cerâmicos Pauluzzi (2017), o qual traz opções na configuração das vedações verticais com diferentes blocos cerâmicos e espessuras no revestimento de argamassa. As configurações das paredes de alvenaria adotadas para o atendimento dos níveis de

\section{INTER/SCIENTIA}

REVISTA INTERSCIENTIA | V. 7 | N. 2 | P. 4-26 | JUL-DEZ/2019 
desempenho adequados e seus respectivos índices de redução sonora ponderado estão apresentados a seguir na tabela 9.

Tabela 9 - Configuração dos sistemas de paredes de alvenaria adotados

\begin{tabular}{|c|c|c|c|}
\hline $\begin{array}{l}\text { Elemento (nível de } \\
\text { desempenho) }\end{array}$ & Configuração da vedação vertical & $\mathbf{R}_{\mathrm{w}}(\mathrm{dB})$ & Custo (R\$)/ $\mathrm{m}^{2}$ \\
\hline $4(M)$ & $\begin{array}{c}\text { Bloco de vedação } 9 \times 19 \times 29+1,5 \mathrm{~cm} \text { de reboco em } \\
\text { ambas as faces }\end{array}$ & 39 & $\mathrm{R} \$ 152,70$ \\
\hline $4(1)$ & $\begin{array}{c}\text { Bloco estrutural } 14 \times 19 \times 29+2,5 \mathrm{~cm} \text { de reboco (c/ } \\
\text { chapisco) em uma face e } 1 \mathrm{~cm} \text { de reboco na } \\
\text { outra }\end{array}$ & 41 & $\mathrm{R} \$ 180,73$ \\
\hline $1(M), 3(M), 4(S)$ e 7 & $\begin{array}{c}\text { Bloco estrutural } 14 \times 19 \times 29+3 \mathrm{~cm} \text { de reboco em } \\
\text { ambas as faces }\end{array}$ & 45 & $\mathrm{R} \$ 178,36$ \\
\hline $1(I)$ e $3(I)$ & $\begin{array}{c}\text { Bloco estrutural } 14 \times 19 \times 29+0,5 \mathrm{~cm} \text { de chapisco e } \\
3 \mathrm{~cm} \text { de reboco em ambas as faces }\end{array}$ & 50 & $\mathrm{R} \$ 205,74$ \\
\hline $1(S)$ e $3(S)$ & $\begin{array}{c}\text { Bloco estrutural } 19 \times 19 \times 29 \text { preenchido com areia } \\
+2,5 \mathrm{~cm} \text { de reboco externo e } 1,5 \mathrm{~cm} \text { de reboco } \\
\text { interno }\end{array}$ & 55 & $R \$ 193,55$ \\
\hline
\end{tabular}

Fonte: adaptados por autores (2019) de Pauluzzi (2017) e SINAPI (2018)

\subsection{Divisórias de drywall}

A Associação Brasileira do Drywall (2015) destaca a eficácia do sistema massa-mola-massa, e traz a lã mineral como alternativa para redução do índice de redução sonora ponderado e o aumento do vão entre as placas, aumentando a quantidade de ar, que também funciona como mola no sistema. As configurações para as divisórias internas de drywall foram determinadas utilizando o manual de desempenho acústico da Associação Brasileira do Drywall (2015) como referência. As configurações das paredes de drywall adotadas para o atendimento dos níveis de desempenho adequados e seus respectivos índices de redução sonora ponderado estão apresentados na tabela 10.

Tabela 10 - Configuração dos sistemas de paredes de drywall adotados

\begin{tabular}{|c|c|c|c|}
\hline $\begin{array}{l}\text { Elemento (nível } \\
\text { de desempenho) }\end{array}$ & Configuração da vedação vertical & $\begin{array}{l}R_{w} \\
(d B)\end{array}$ & $\begin{array}{c}\text { Custo (RS)/ } \\
\mathrm{m}^{2}\end{array}$ \\
\hline $4(M)$ & $\begin{array}{c}\text { Parede de } 7,3 \mathrm{~cm} \text {, com duas chapas de } 1,25 \mathrm{~cm} \text { de } \\
\text { espessura separada por } 4,8 \mathrm{~cm}\end{array}$ & 36 & $R \$ 91,86$ \\
\hline $4(1)$ & $\begin{array}{l}\text { Parede de } 7,3 \mathrm{~cm} \text {, com duas chapas de } 1,25 \mathrm{~cm} \text { de } \\
\text { espessura separada por } 4,8 \mathrm{~cm} \text { preenchida com lã } \\
\text { mineral }\end{array}$ & 44 & $\mathrm{R} \$ 113,33$ \\
\hline $1(M), 3(M)$ e $4(S)$ & $\begin{array}{c}\text { Parede de } 9,5 \mathrm{~cm} \text {, com duas chapas simples de } 1,25 \mathrm{~cm} \\
\text { de espessura separada por } 7 \mathrm{~cm} \text { preenchida com lã } \\
\text { mineral }\end{array}$ & 45 & $R \$ 116,43$ \\
\hline
\end{tabular}

\section{INTER SCIENTIA}

REVISTA INTERSCIENTIA | V. 7 | N. 2 | P. 4-26 | JUL-DEZ/2019 


\begin{tabular}{cccc}
\hline $1(I)$ e 3(I) & $\begin{array}{c}\text { Parede de 12 cm, com duas chapas de dupla estrutura } \\
\text { de } 1,25 \mathrm{~cm} \text { de espessura separada por } 7 \mathrm{~cm} \text { preenchida } \\
\text { com lã mineral }\end{array}$ & 51 & $\mathrm{R} \$ 170,07$ \\
\hline $1(S)$ e 3(S) & $\begin{array}{c}\text { Parede de } 19,3 \mathrm{~cm} \text {, com duas chapas de dupla } \\
\text { estrutura de } 1,25 \mathrm{~cm} \text { de espessura separada por } 14,3 \mathrm{~cm} \\
\text { preenchida com lã mineral }\end{array}$ & 61 & $\mathrm{R} \$ 198,24$ \\
\hline
\end{tabular}

Fonte: adaptados por autores (2019) de Associação Brasileira do Drywall (2015) e SINAPI (2018)

\subsubsection{LEVANTAMENTO DOS MATERIAIS NECESSÁRIOS}

Após determinadas todas as configurações de sistemas de pisos e de vedações verticais necessárias para o atendimento dos três níveis de desempenho ( $M$, I e S), foi feito um levantamento da quantidade dos materiais necessários, conforme medição do projeto. Os valores são para todo o edifício, ou seja, são o somatório de seis pavimentos tipo.

O primeiro levantamento foi feito para os sistemas de pisos e os valores podem ser consultados na tabela 11. Conforme citado no item 4.1.1, o sistema de piso terá igual configuração em toda área do apartamento, para todos os apartamentos, com exceção das áreas molhadas, onde sempre serão revestidos porcelanato.

Após o levantamento do sistema de pisos, as vedações verticais (internas e externas) com exigências na NBR 15575 (ABNT, 2013) foram medidas, levando em conta cada situação já apresentada na figura 4 . Os valores podem ser consultados na tabela 12.

Tabela 11 - Área de piso

\begin{tabular}{cc}
\hline Classificação & Área $\left(\mathbf{m}^{2}\right)$ \\
\hline Área de piso (exceto áreas molhadas) & 366,08 \\
\hline Áreas de piso molhado & 81,04 \\
\hline \multicolumn{2}{c}{ Fonte: autores (2019) }
\end{tabular}

Tabela 12 - Área útil total das paredes das envoltórias

\begin{tabular}{ccccc}
\hline Classificação & Comprimento $(\mathbf{m})$ & Área total $\left(\mathbf{m}^{2}\right)$ & $\begin{array}{c}\text { Desconto } \\
\text { esquadrias }\left(\mathbf{m}^{2}\right)\end{array}$ & Área útil $\left(\mathbf{m}^{2}\right)$ \\
\hline 1 & 33,2 & 89,64 & 0 & 89,64 \\
\hline 2 & 0 & 0 & 0 & 0 \\
\hline 3 & 7,9 & 21,33 & 0 & 21,33 \\
\hline 4 & 32 & 86,4 & 15,12 & 71,28 \\
\hline 5 & 0 & 0 & 0 & 0 \\
\hline 6 & 0 & 0 & 0 & 0 \\
\hline 7 & 86,5 & 233,55 & 23,04 & 210,51 \\
\hline
\end{tabular}

Fonte: autores (2019) 
Por fim, foi feita a contagem da quantidade de esquadrias que contemplam os sistemas de vedações verticais com exigências na NBR 15575 (ABNT, 2013). Os valores podem ser consultados na tabela 13.

Tabela 13 - Quantidade de esquadrias

\begin{tabular}{cc}
\hline Esquadrias & Quantidade (un) \\
\hline Janelas $120 \times 120 \mathrm{~cm}$ & 96 \\
\hline Portas de madeira $90 \times 210 \mathrm{~cm}$ & 48 \\
\hline
\end{tabular}

Fonte: autores (2019)

\subsubsection{ORÇAMENTO DOS MATERIAIS NECESSÁRIOS}

Tendo todas as medidas definidas e divisórias classificadas, o terceiro passo foi determinar os valores totais para cada elemento analisado anteriormente, sendo que os valores unitários para cada unidade de medida foram apresentados no item 4.1 e os quantitativos no item 4.2. As composições de custos foram feitas a partir de dados obtidos do Sistema Nacional de Pesquisa de Custos e Índices da Construção Civil (SINAPI) da Caixa Econômica Federal e da Tabela de Composições de Preços para Orçamentos (TCPO) da Editora PINI.

Neste orçamento não foram considerados os Benefícios e Despesas Indiretas (BDI), e os encargos social sobre os custos de mão-de-obra acrescidos sobre o custo horário de cada funcionário foi de $113,15 \%$, valor obtido através do relatório de Insumos e Composições de abril de 2018 (não desonerado) do SINAPI.

Na tabela 14 são apresentados os valores totais encontrados para cada elemento e o custo total para os níveis de desempenho mínimo, intermediário e superior. Retomando, foram calculados valores para duas opções de sistemas de vedações verticais internos, alvenaria e drywall, sendo calculado o custo total final para ambos.

Tabela 14 - Resultados dos custos para os três níveis de desempenho

\begin{tabular}{cccccc}
\hline $\begin{array}{c}\text { Nível de } \\
\text { Desempenho }\end{array}$ & \multicolumn{2}{c}{ S. Vedações Verticais } & S. Pisos & Esquadrias & Custo total \\
\hline \multirow{2}{*}{ Mínimo } & Alvenaria & $\mathrm{R} \$ 409.331,56$ & $\mathrm{R} \$ 1.084 .911,97$ & $\mathrm{R} \$ 265.632,37$ & $\mathrm{R} \$ 1.759 .875,90$ \\
& Drywall + Alvenaria & $\mathrm{R} \$ 342.081,31$ & & $\mathrm{R} \$ 1.692 .625,65$ \\
\hline \multirow{2}{*}{ Intermediário } & Alvenaria & $\mathrm{R} \$ 439.369,18$ & $\mathrm{R} \$ 1.172 .816,64$ & $\mathrm{R} \$ 322.272,37$ & $\mathrm{R} \$ 1.934 .458,19$ \\
& Drywall + Alvenaria & $\mathrm{R} \$ 386.978,34$ & & $\mathrm{R} \$ 1.882 .067,35$ \\
\hline \multirow{2}{*}{ Superior } & Alvenaria & $\mathrm{R} \$ 430.425,64$ & $\mathrm{R} \$ 885.982,47$ & $\mathrm{R} \$ 368.352,21$ & $\mathrm{R} \$ 1.684 .760,32$ \\
& Drywall + Alvenaria & $\mathrm{R} \$ 407.059,28$ & & $\mathrm{R} \$ 1.661 .393,95$ \\
\hline
\end{tabular}

Fonte: autores (2019) 


\section{ANÁLISE DOS RESULTADOS OBTIDOS}

Atendendo as composições de custos concluídas, é possível uma comparação de custos. A figura 9 traz uma comparação gráfica, onde foram considerados os custos de todos elementos analisados (vedações verticais, sistemas de pisos e esquadrias), conforme resultados obtidos na tabela 14. Na figura, é possível perceber a diferença, no mesmo nível de desempenho, entre o uso de alvenaria em toda edificação e o uso de drywall nas vedações internas, como também a diferença entre os níveis de desempenho.

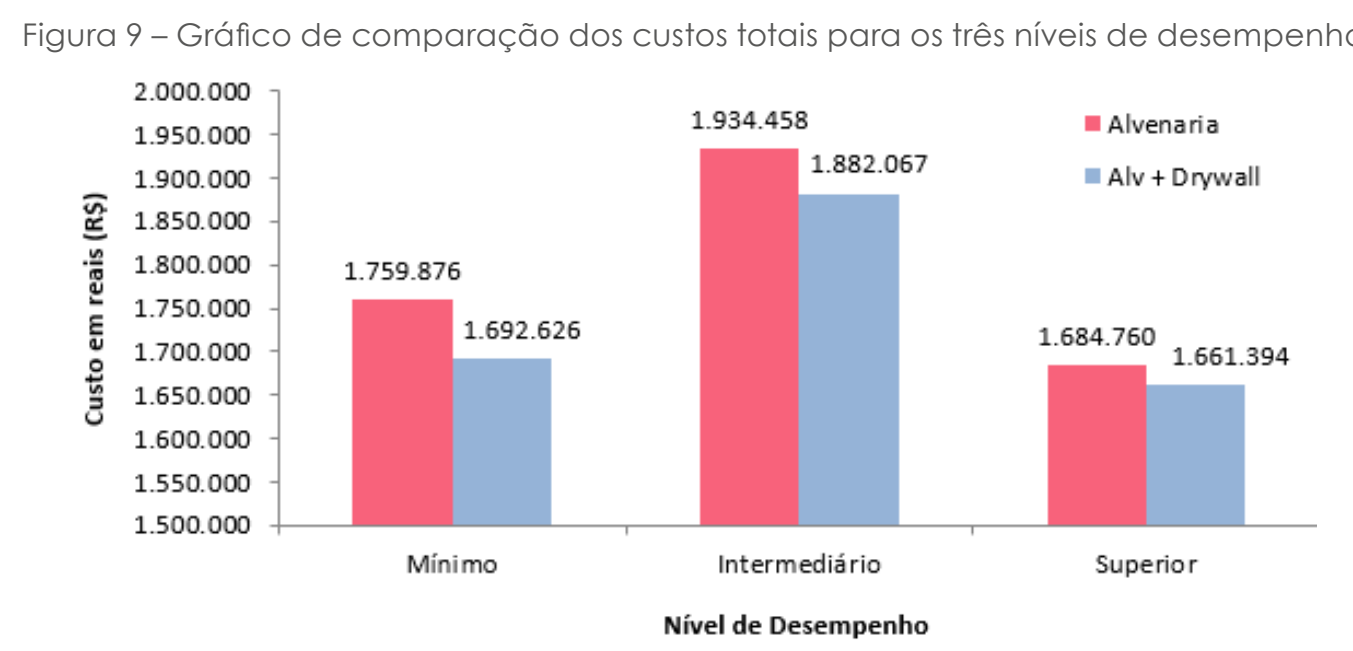

A utilização de placas de drywall como elemento de vedação interna teve, nos custos, uma pequena vantagem sobre o uso apenas de alvenaria. $O$ uso de drywall apresentou uma economia de aproximadamente $3,82 \%$ no nível de desempenho mínimo, e de $2,71 \%$ e $1,39 \%$ nos níveis intermediário e superior, respectivamente. Analisando o gráfico da figura 10, é possível perceber que a diferença no custo da mão de obra para o sistema de drywall é quase $35 \%$ mais baixo que quando utilizado apenas alvenaria $(34,51 \%, 35,11 \%$ e $32,86 \%$ para os níveis $\mathrm{M}, \mathrm{I}$ e S, respectivamente), ou seja, a pequena diferença no custo total é devido ao mais alto custo do material utilizado no sistema de placas de drywall, e a mais rápida execução torna o custo de mão de obra mais baixo. 
Figura 10- Gráfico de comparação dos custos de mão de obra dos SVVIE para os três níveis de desempenho

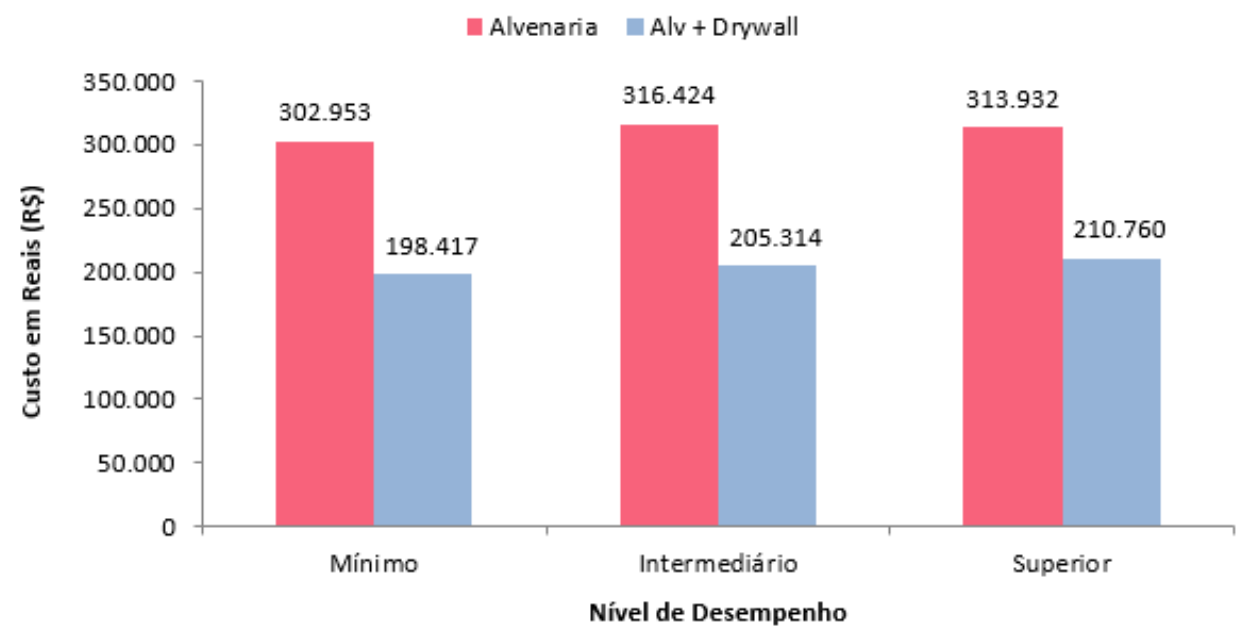

A diferença de custos entre os níveis $M, I$ e $S$ merece uma análise mais detalhada, principalmente pelo nível superior ter apresentado menor custo em relação aos menores níveis de desempenho (figura 9). Primeiramente, analisando o uso de placas de drywall, o orçamento para o nível superior demonstrou uma economia de 1,85\% sobre o nível mínimo e de 11,72\% sobre o nível intermediário, já o nível mínimo demostrou economia de 10,07\% sobre o nível intermediário. Ao analisar o uso de alvenaria em todo o pavimento, o nível superior teve custo $4,27 \%$ mais baixo que o nível mínimo e 12,91\% que o nível intermediário, já o mínimo representou custo $9,02 \%$ abaixo do intermediário.

A vantagem no custo apresentada pelo nível superior de desempenho foi dada devido às configurações adotadas nos sistemas de pisos, percebe-se ao analisar os gráficos das figuras 11 e 12. A solução adotada para o sistema de pisos do nível superior de desempenho acústico é mais barata, mesmo trazendo mais benefícios de redução sonora. Conforme Tenório et al. (2009), as lajes nervuradas requerem menos consumo de concreto e aço, assim como menor índice de formas, reduzindo o custo de material e mão de obra, porém, segundo Rizzatti (2017), elas ainda são pouco utilizadas, em comparação com outros tipos de laje, devido a sua execução requerer mais atenção.

Quando comparado apenas o SVVIE (Figura 11), o nível superior tem o custo mais elevado e o mínimo o mais baixo, seguindo a tendência esperada. Diferente do sistema de pisos, onde a camada de maior impacto no custo não seguiu o mesmo método em todos os níveis de desempenho, os métodos construtivos utilizados no SVVIE foram os mesmo para os três níveis de desempenho, as diferenças nos níveis se deram por alguns detalhes de espessura e acabamentos. O acréscimo do preço para a solução que atende ao nível superior, quando considerado vedações internas de drywall, é de 9,33\% e 27,59\% em relação aos níveis intermediário e mínimo, respectivamente. Já o acréscimo para o nível intermediário em relação ao 
nível mínimo é de 16,71\%. Considerando apenas alvenaria, os acréscimos do o nível superior sobre o intermediário e mínimo são, respectivamente, 4,88\% e 18,34\%, e do intermediário sobre o mínimo é de 12,84\%.

Figura 11 - Gráfico de comparação dos custos dos SVVIE para os três níveis de desempenho

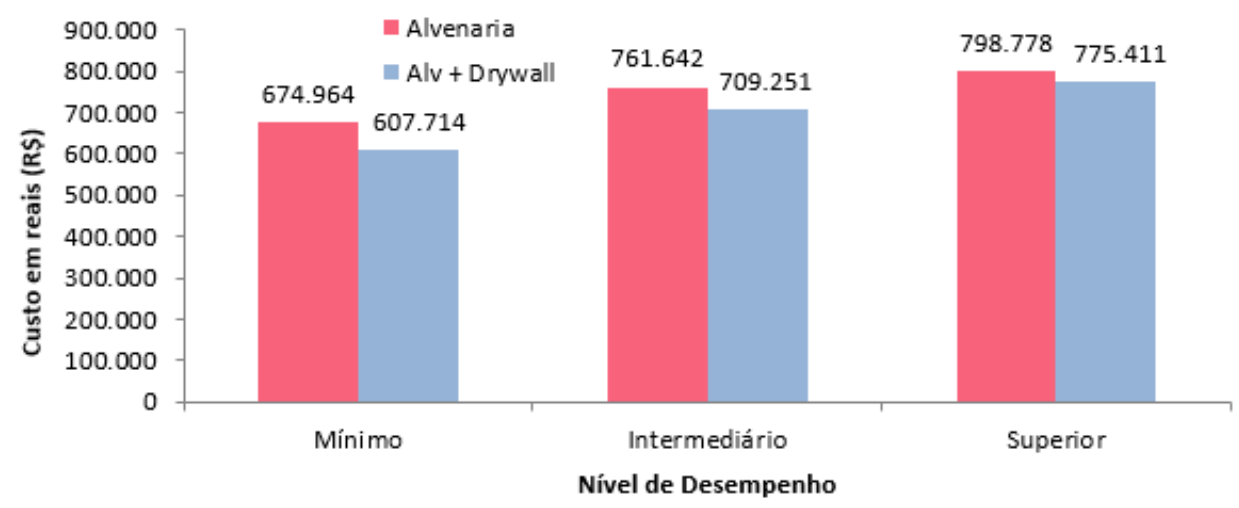

Figura 12 - Gráfico de comparação dos custos dos sitemas de pisos para os três níveis de desempenho

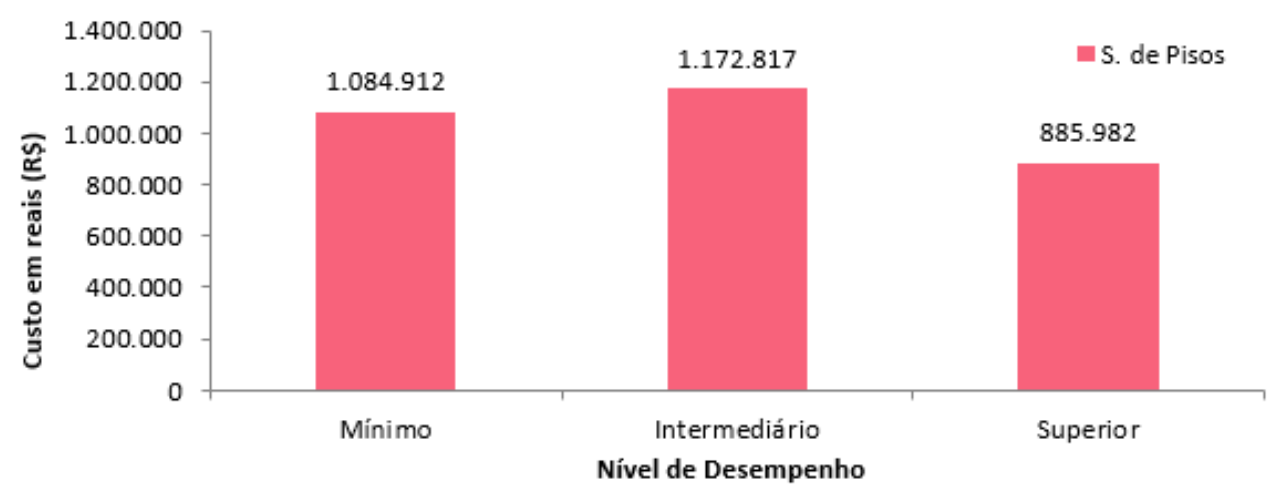

\section{CONSIDERAÇÕES FINAIS}

Este artigo visou a análise do custo de uma edificação para que atenda cada um dos três níveis de desempenho acústico (M, I e S) para vedações verticais externas, vedações verticais internas e sistema de pisos, seguindo as especificações da NBR 15575 (ABNT, 2013).

Ao analisar os resultados obtidos, percebe-se que a estimativa de custos para nível superior de desempenho teve um resultado abaixo da dos níveis de menor eficiência acústica, apresentando uma economia de aproximadamente $12 \%$ sobre o nível intermediário e entre $1 \%$ e $4 \%$ sobre o nível mínimo, lembrando que foram feitas análises para dois tipos de materiais nas divisórias internas. O mais baixo custo do nível superior se deu devido a escolha da configuração do sistema de pisos, pois o tipo de camada estrutural adotada foi diferente dos níveis mínimo e 
intermediário. Seria necessário fazer uma comparação onde o tipo de laje adotado seja o mesmo nos três projetos cabendo futuramente uma melhor análise.

Quando analisado apenas o SVVIE, foi percebido que o custo aumentou a medida do desempenho acústico se tornava mais eficiente, isto foi percebido com o uso de drywall nas vedações internas e com os usos de alvenaria em toda as vedações verticais. Está análise foi feita separadamente para os dois tipos de materiais utilizados nas paredes internas. O uso de placas de drywall levou vantagem em todos os níveis analisados, apresentando uma economia entre $1 \%$ e $4 \%$ sobre o uso de alvenaria em toda a edificação, representando uma variação pequena entre os três níveis de desempenho. Porém, analisando o custo de mão de obra, a diferença chega a aproximadamente $35 \%$, ou seja, o custo do material para o sistema de drywall é mais elevado, porém a execução é mais rápida.

Como sugestão para o aprimoramento deste estudo, deve-se analisar o impacto no custo do sistema de pisos para o atingimento dos níveis de desempenho mínimo, intermediário e superior sem diferença no tipo de laje da camada estrutural. As alterações feitas para o atingimento de melhores desempenhos podem ser na altura desta camada ou nos materiais que compreendem as outras camadas.

\section{REFERÊNCIAS}

ASSOCIAÇÃO BRASILEIRA DE NORMAS TÉCNICAS (ABNT). NBR 10821-4: Esquadrias para edificações - Parte 4: Requisitos adicionais de desempenho. Rio de Janeiro, 2017.

ASSOCIAÇÃO BRASILEIRA DE NORMAS TÉCNICAS (ABNT). NBR 15575-1: Desempenho de edificações habitacionais - Parte 1: Requisitos gerais. Rio de Janeiro, 2013.

ASSOCIAÇÃO BRASILEIRA DE NORMAS TÉCNICAS (ABNT). NBR 15575-3: Desempenho de edificações habitacionais - Parte 4: Requisitos para os sistemas de pisos. Rio de Janeiro, 2013.

ASSOCIAÇÃO BRASILEIRA DE NORMAS TÉCNICAS (ABNT). NBR 15575-4: Desempenho de edificações habitacionais - Parte 4: Requisitos para os sistemas de vedações verticais internas e externas. Rio de Janeiro, 2013.

ASSOCIAÇÃO BRASILEIRA DO DRYWALL. Desempenho acústico em sistemas drywall. 2. ed. São Paulo, 2015.

BORGES, Carlos Alberto de Morais. O conceito de desempenho de edificações e a sua importância para o setor da construção civil no Brasil. 2008. 263 f. Dissertação (Mestrado em Engenharia) - Escola Politécnica, Universidade de São Paulo, São Paulo, 2008. 
CÂMERA BRASILEIRA DA INDUSTRIA DA CONSTRUÇÃO (CBIC), Desempenho de edificações habitacionais. Guia de orientação para atendimento a norma NBR 15575. Distrito Federal, 2013.

CÂMERA BRASILEIRA DA INDUSTRIA DA CONSTRUÇÃO (CBIC), Esquadrias para Edificações: desempenho e aplicações. Guia de orientação para atendimento a norma NBR 15575. Distrito Federal, 2017.

CARVALHO, Régis Paganio. Acústica Arquitetônica. Brasília: Thesaurus Editora, 2006, $167 \mathrm{p}$.

COELHO, Rafael Vigário. Análise de custo para a implantação dos níveis de desempenho acústico da NBR 15575 em sistemas de vedações verticais. 2017. 47 f. Trabalho de Conclusão de Curso (Graduação em Engenharia Civil) - Centro de Ciências Tecnológicas, Fundação Universidade Regional de Blumenau, Blumenau, 2017.

CORDOVIL, Luiz Augusto Berger Lopes. Estudos da ABNT NBR 15575 - "Edificações habitacionais - Desempenho" e possíveis impactos no setor da construção civil na cidade do Rio de Janeiro. 2013. Projeto de Graduação (Graduação em Engenharia Civil) - Escola Politécnica, Universidade Federal do Rio de Janeiro, Rio de Janeiro, 2013

LIMA, Gabriela Crestani de. Influência no desempenho acústico de uma esquadria de alumínio a partir de modificação em sua caixa de persiana. 2017. Trabalho de Conclusão de Curso (Graduação em Engenharia Civil) - Faculdade de Engenharia, Pontifícia Universidade Católica do Rio Grande do Sul, Porto Alegre, 2017.

MICHALSKI, Ranny Loureiro Xavier Nascimento. Metodologias para a medição de isolamento sonoro em campo e para a expressão da incerteza de medição na avaliação do desempenho acústico de edificação. 2011. Tese (Doutorado em Engenharia Mecânica) - COPPE, Universidade Federal do Rio de Janeiro, Rio de Janeiro, 2011.

NIENKOETTER, Gustavo Martins et al. Impacto do tratamento a cústico de lajes no custo das edificações residenciais do CUB. In: IX ENCONTRO NACIONAL DE TECNOLOGIA DO AMBIENTE CONSTRUÍDO, 2014, Maceió. Anais... Florianópolis: Universidade Federal de Santa Catarina, 2014. p. 1206-1215

OLIVEIRA, Maria Fernanda de; ZINI, Aline; PAGNUSSAT, Daniel Tregnago. Desempenho Acústico de Sistemas de Piso: Estudos de Caso Para Isolamento ao Ruído Aéreo e de Impacto. Revista da Sociedade Brasileira de Acústica, [s.I], v. 1, n. 46, p.13-19, dez. 2014. 
PAULUZZI PRODUTOS CERÂMICOS LTDA. Desempenho: sistemas de alvenaria com blocos cerâmicos Pauluzzi. Sapucaia do Sul, 2017.

POLLI, Taiana; VIVEIROS, Elvira B. Quando o preço não faz diferença: a relação entre custo do imóvel e conforto acústico. In: IX ENCONTRO NACIONAL E V LATINO AMERICANO DE CONFORTO NO AMBIENTE CONSTRUÍDO, 2007, Ouro Preto. Anais... . Florianópolis: Universidade Federal de Santa Catarina, 2007. p. 1529-1538.

REZENDE, Jardel Masciocchi Silva; FILHO, Júlio César Gomes de Morais; NASCIMENTO, Néio Lúcio Freitas. O desempenho acústico segundo a norma de desempenho ABNT NBR 15 575: Isolamento sonoro contra o ruído aéreo de vedações verticais internas medido em campo. 2014. Trabalho de Conclusão de Curso (Graduação em Engenharia Civil) - Universidade Federal de Goiás, Goiânia, 2014.

RIZZATTI, Lorenzo Sartori. Lajes nervuradas: projeto, execução e análise de patologias. 2017. 74 f. TCC (Graduação) - Curso de Engenharia Civil, Universidade Federal de Santa Maria, Santa Maria, 2017.

SINDICATO DA INDÚSTRIA DA CONSTRUÇÃO CIVIL (SINDUSCON), Avaliação do desempenho acústico de edificações em diferentes sistemas construtivos. Guia de orientação para atendimento a Norma de Desempenho. Distrito Federal, 2015.

STRADIOTTO, Júlia. A influência da argamassa no desempenho acústico de paredes de vedação com blocos cerâmicos. 2016. 20 f. Monografia (Especialização) Curso de Especialização em Construção Civil, Universidade do Vale dos Sinos, São Leopoldo, 2016.

TCPO, Tabela de composição de preços para orçamentos - $13^{a}$ ed. - São Paulo: Pini, 2008.

TENÓRIO, Daniel Almeida et al. Aspectos Técnicos e Econômicos de Lajes Nervuradas Unidirecionais e Bidirecionais. In: $51^{\circ}$ CONGRESSO BRASILEIRO DO CONCRETO, 51. 2009, Curitiba. Anais.... Maceió: ISBN, 2009. p. 1 - 16. 